\title{
Psychometric analysis of stress, anxiety and depression in patients with recurrent aphthous Stomatitis-A cross-sectional survey based study
}

\author{
Ashwini Dhopte ${ }^{1}$, Giridhar Naidu ${ }^{2}$, Ramanpal Singh-Makkad ${ }^{3}$, Ravleen Nagi ${ }^{4}$, Hiroj Bagde ${ }^{5}$, Supreet Jain ${ }^{6}$ \\ ${ }^{1}$ Post Graduate Student, Department of Oral Medicine and Radiology \\ ${ }^{2}$ Professor and Head of the Department, Department of Oral Medicine and Radiology \\ ${ }^{3}$ Associate Professor, Department of Oral Medicine and Radiology \\ ${ }^{4}$ Associate Professor, Department of Oral Medicine and Radiology \\ ${ }^{5}$ Assistant Professor, Department of Periodontology \\ ${ }^{6}$ Assistant Professor, Department of Oral Medicine and Radiology
}

Correspondence:

Department of oral Medicine and Radiology

New Horizon Dental College and Research Institute

Sakri, Bilaspur

ashwinidhopte@gmail.com

Dhopte A, Naidu G, Singh-Makkad R, Nagi R, Bagde H, Jain S. Psychometric analysis of stress, anxiety and depression in patients with recurrent aphthous Stomatitis-A cross-sectional survey based study. J Clin Exp Dent. 2018;10(11):e1109-14.

http://www.medicinaoral.com/odo/volumenes/v10i11/jcedv10i11p1109.pdf

Received: $14 / 05 / 2018$ Accepted: $15 / 10 / 2018$

\begin{abstract}
Background: Recurrent Aphthous Stomatitis is a chronic inflammatory immune mediated condition associated with single or multiple, painful recurring ulcers of the oral mucosa. Psychological stress is a common trigger factor identified for the onset and progression of this condition. The study aimed to evaluate stress, anxiety and depression using the Hospital Anxiety and Depression scale and stress by the General Health Questionnaire in subjects with Recurrent Aphthous Stomatitis (RAS).

Material and Methods: The study evaluated subjects with a history of Recurrent Aphthous Stomatitis and compared their psychological stress, anxiety and depression alteration to normal subjects. Seventy-five study subjects were divided into three groups; test group 1 ( 25 subjects) presenting with RAS, test group 2 ( 25 subjects) with a history of RAS but without oral ulcers, and 25 normal subjects with no history of RAS formed the control group. Chi square and student $t$ test was used to determine the relationship between psychological variables and recurrent aphthous ulcers.

Results: Comparison of stress, Anxiety and Depression between test group 1 and control group, test group 2 and control group was not found to be statistically significant $(p<0.05)$. Hence, differences were evident when individual questions were analyzed for stress anxiety and depression. Stress and depression were more prevalent in females, students and patients with a history of RAS.

Conclusions: Higher depression and stress levels were evident in subjects with a history of RAS. Psychological stress is a utmost trigger factor for the initiation of recurrent ulcers. Overall, test group patients had a more psychological impact on the quality of life than the control group.
\end{abstract}

Key words: Anxiety, depression, General Health Questionnaire, Hospital Anxiety and Depression scale, Recurrent Aphthous Stomatitis, stress. 


\section{Introduction}

Recurrent aphthous stomatitis (RAS) or canker sore is painful and ulcerative disorder of the oral mucosa, affecting $5-25 \%$ of the general population characterized by recurrent, small, round or ovoid ulcers with circumscribed margins, erythematous halo and yellow or grayish floor, common in childhood or adolescence (1). The exact etiopathogenesis is still not clear, but evidence from the existing literature suggests focal immune dysfunction involving $\mathrm{T}$ cell mediated immunity as a key mechanism in the development of Recurrent Aphthous ulcer. Clinicians should also identify triggers or causative factors for proper management of this condition. Acute psychological disorders (e.g. Stress and anxiety) were found to be most commonly associated with the onset and progression of RAS as severe stress provokes immune-regulatory activity by increasing the number of leukocytes at sites of inflammation (2).

It is well recognized that the symptoms caused by recurrent aphthous stomatitis, such as pain during speaking, eating, and swallowing; discomfort; impairment in food and liquid intake; and problems in interpersonal relationships and self-esteem can deeply affect the oral health-related quality of life of patients (3). Oral health and psychological status has profound impact on people's daily living, quality of life and overall well-being, therefore, the clinical status, psychological factors, dental needs and patient's perceptions should be assessed (2). Taking above into consideration, this study was conducted to evaluate anxiety and depression using the Hospital Anxiety and Depression scale (4) and stress by General Health Questionnaire (5) in subjects presenting with Recurrent Aphthous Stomatitis and those having history of RAS but not presenting with an ulcer at present and were compared with controls.

\section{Material and Methods}

The study enrolled Seventy-five subjects aged 15-50 years selected from the outpatient department of Oral Medicine and Radiology, New Horizon Dental College and Research Institute, Bilaspur, Chhattisgarh, India, after obtaining their informed consent. A Study was conducted from December 2015 to June 2017 and ethical clearance was obtained from the ethical committee of the institute. Patients presenting with one or more active ulcer ( $<48$ hours duration) measuring no more than 10 $\mathrm{mm}$ in diameter were included and patients with artificial pace makers, malignant diseases, history of systemic disease i.e. HIV, anemia, mutational defects ,diabetes mellitus, etc or any condition that could predispose to oral ulceration, ulcers caused due to topical or systemic medications or currently under treatment with any topical medication or corticosteroids, pregnant or lactating women and chronic smokers were excluded from the study.
Seventy-five subjects were divided into three groups, test Group 1 (25 Subjects) presenting with RAS, test Group 2 (25 Subjects) with a history of RAS but not presenting with an ulcer at present, and 25 normal healthy adults with no history of RAS were selected as controls. Detailed case history was taken and were asked to fill General Health Questionnaire (GHQ) and Hospital Anxiety and Depression scale (HAD) questionnaire in English and Hindi language. Data gathered from completing questionnaires was scored and tabulated after it was entered into Microsoft excel spreadsheet and statistical analysis was done by using Statistical package of social science (SPSS session 21, SPSS Inc., Chicago, IL, USA). Chi square and student $t$ test was used to determine the relationship between psychological variables and recurrent aphthous ulcers. P value $<0.05$ was considered to be statistically significant.

\section{Results}

The mean age of the RAS patients in test group was 23.5 years and control group was 24.4 years. Out of 75 subjects, there were $33.3 \%$ males, and $66.7 \%$ females, with a male to female ratio of 1:2. Both RAS patients and controls reported comparable depression, anxiety, stress scores, that were statistically not significant $(p>0.05)$. For RAS patients (test group 1), mean anxiety $(8.04 \pm$

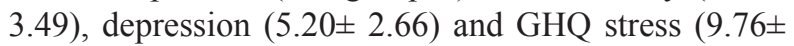
4.52) scores were slightly higher than the control group where the scores were $7.04 \pm 5.10,3.96 \pm 2.93$ and $9.72 \pm$ 5.0 respectively. The findings indicate that RAS patients had higher levels of anxiety, stress and depression than the control group as in table 1 .

For patients with previous history of RAS (test group 2), mean GHQ stress (11.48 \pm 5.66$)$ and depression (5.36 \pm 3.18) score were higher than the control group for which the scores were $9.72 \pm 5.01$ and $3.96 \pm 2.93$, respectively whereas mean anxiety scores for test group 2 of $6.12 \pm$ 3.14 was found to be slightly less than the controls of $7.04 \pm 5.10$ as shown in table 2 . This suggested higher levels of stress and depression in patients with history of RAS in comparison to controls that were slightly more anxious.

The results obtained for the study regarding stress, anxiety and depression amongst both the groups had an impact on the overall health of the individual and also has triggering effect for RAS as shown in figures 1-3.

Results showed that mental stress had a larger effect on females than males and higher scores of stress, anxiety and depression were seen in students as compared to other profession and housewives. When a comparison was made between groups, there was no statistical significant difference noted in levels of anxiety, stress and depression, however, the differences in response became evident when individual questions were analyzed for stress, anxiety and depression as shown in table 3, 4 . 
Table 1: Comparison of psychological factors between test group 1 (cases with ulcers) and control group.

\begin{tabular}{|l|c|c|c|c|c|}
\hline & Groups & $\begin{array}{c}\text { Number of } \\
\text { patients }\end{array}$ & Mean & $\begin{array}{c}\text { Standard } \\
\text { deviation }\end{array}$ & P value \\
\hline \multirow{2}{*}{ HAD-Anxiety } & cases with ulcers & 25 & 8.0400 & 3.49380 & 0.066 \\
\cline { 2 - 6 } & Controls & 25 & 7.0400 & 5.10294 & \\
\hline \multirow{2}{*}{ HAD-Depression } & cases with ulcers & 25 & 5.2000 & 2.66145 & \\
\cline { 2 - 6 } & Controls & 25 & 3.9600 & 2.93655 & 0.711 \\
\hline \multirow{2}{*}{ GHQ-stress } & cases with ulcers & 25 & 9.7600 & 4.52106 & 0.526 \\
\cline { 2 - 6 } & Controls & 25 & 9.7200 & 5.01265 & \\
\cline { 2 - 6 } Age & cases with ulcers & 25 & 27.2400 & 8.38789 & 0.004 \\
\hline
\end{tabular}

*HAD $=$ Hospital Anxiety and Depression, $\mathrm{GHQ}=$ General Health Questionnaire

Table 2: Comparison of psychological factors between test group 2 (cases with history of ulcer) and control group.

\begin{tabular}{|c|c|c|c|c|c|c|}
\hline & Groups & $\begin{array}{c}\text { Number of } \\
\text { patients }\end{array}$ & Mean & $\begin{array}{l}\text { Standard } \\
\text { deviation }\end{array}$ & $\begin{array}{c}\text { Standard } \\
\text { Error Mean }\end{array}$ & $P$ value \\
\hline \multirow[t]{2}{*}{ HAD-Anxiety } & cases without ulcers & 25 & 6.1200 & 3.14006 & 0.62801 & \\
\hline & Controls & 25 & 7.0400 & 5.10294 & 1.02059 & 0.083 \\
\hline \multirow[t]{2}{*}{ HAD-Depression } & cases without ulcers & 25 & 5.3600 & 3.18695 & 0.63739 & \\
\hline & Controls & 25 & 3.9600 & 2.93655 & 0.58731 & 0.498 \\
\hline \multirow[t]{2}{*}{ GHQ-stress } & cases without ulcers & 25 & 11.4800 & 5.66510 & 1.13302 & \\
\hline & Controls & 25 & 9.7200 & 5.01265 & 1.00253 & 0.397 \\
\hline \multirow[t]{2}{*}{ Age } & cases without ulcers & 25 & 23.5600 & 2.61534 & 0.52307 & \\
\hline & Controls & 25 & 24.4400 & 4.20397 & 0.84079 & 0.349 \\
\hline
\end{tabular}

*HAD $=$ Hospital Anxiety and Depression, $\mathrm{GHQ}=$ General Health Questionnaire

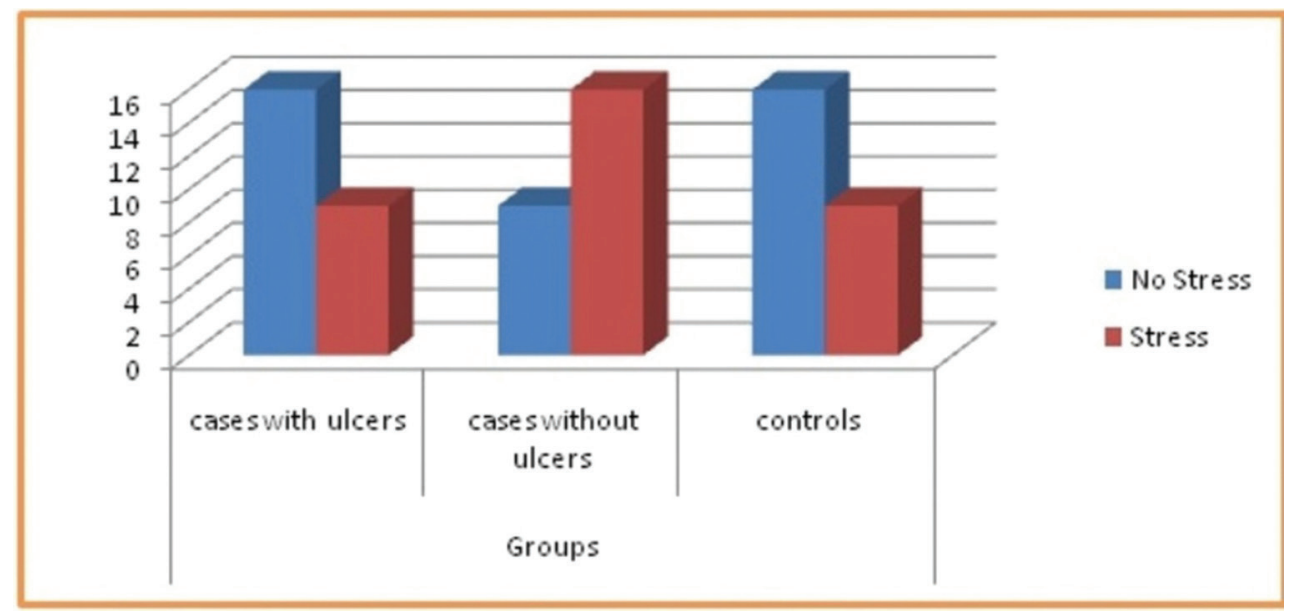

Fig. 1: Distribution of subjects among group for Stress using scoring criteria. 


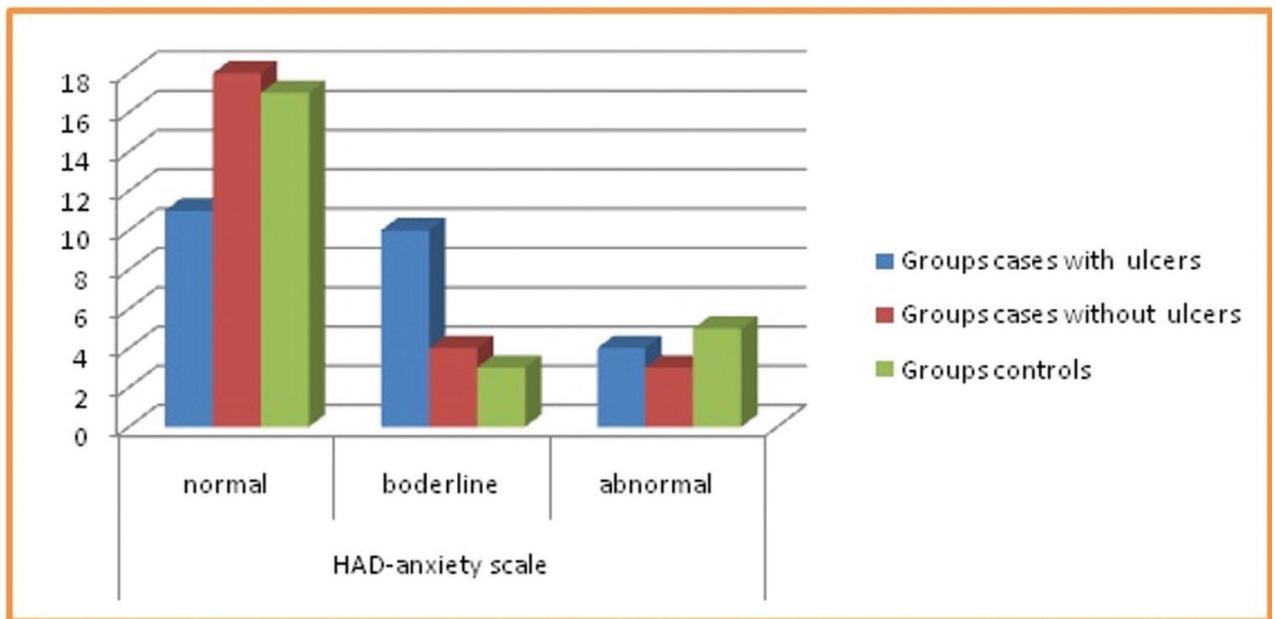

Fig. 2: Distribution of subjects among groups for Anxiety using scoring criteria.

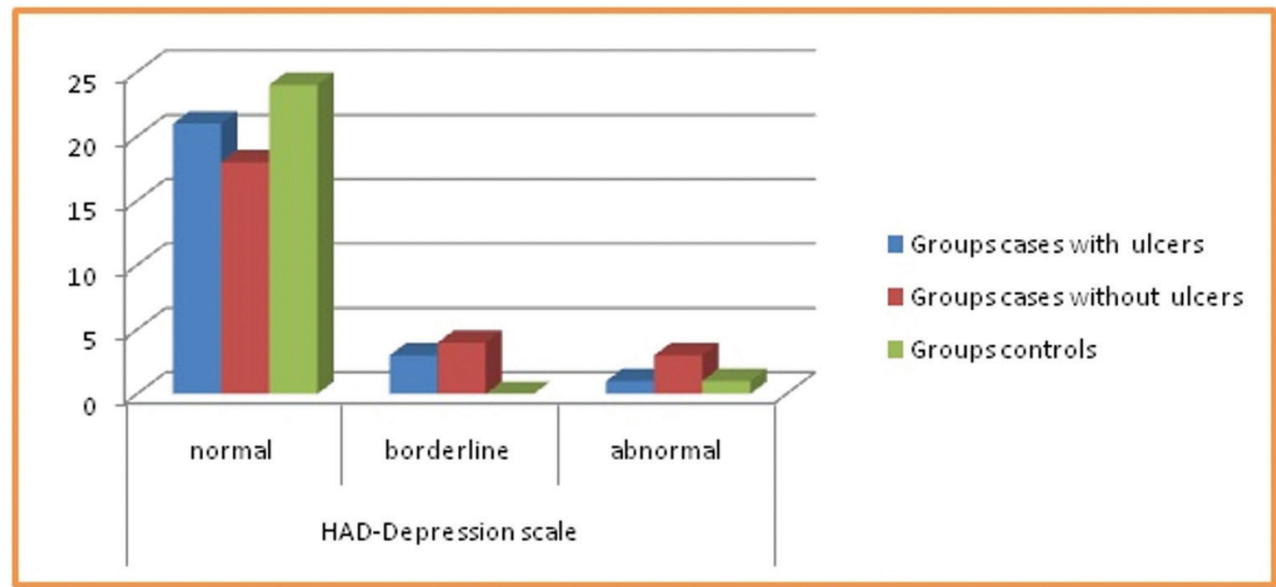

Fig. 3: Distribution of subjects among groups for depression using scoring criteria.

Table 3: Comparison of responses among groups for psychological stress by GHQ questionnaire.

\begin{tabular}{|c|c|c|c|}
\hline GHQ 12 & WITH ULCER & WITHOUT ULCER & CONTROLS \\
\hline 1. Been able to concentrate on what you are doing? & $16 \%$ & $20 \%$ & $4 \%$ \\
\hline 2. Lost much sleep over worry? & $20 \%$ & $28 \%$ & $20 \%$ \\
\hline 3. Felt that you are playing a useful part in things? & $16 \%$ & $20 \%$ & $8 \%$ \\
\hline 4. Felt capable of making decisions about things? & $16 \%$ & $24 \%$ & $4 \%$ \\
\hline 5. Felt constantly under strain & $4 \%$ & $32 \%$ & $12 \%$ \\
\hline 6.Felt you couldn't overcome your difficulties & $4 \%$ & $8 \%$ & $0 \%$ \\
\hline 7.Been able to enjoy your normal day to day activities & $16 \%$ & $20 \%$ & $12 \%$ \\
\hline 8.Been able to face up to your problems & $12 \%$ & $12 \%$ & $4 \%$ \\
\hline 9.Been feeling unhappy and depressed & $8 \%$ & $12 \%$ & $8 \%$ \\
\hline 10. Been losing confidence in yourself? & $12 \%$ & $12 \%$ & $8 \%$ \\
\hline 11.Been thinking of yourself as a worthless person & $0 \%$ & $12 \%$ & $0 \%$ \\
\hline 12.Been feeling reasonably happy all things considered & $4 \%$ & $4 \%$ & $0 \%$ \\
\hline
\end{tabular}

* GHQ= General Health Questionnaire 
Table 4: Comparison of responses among groups for anxiety and depression by Hospital anxiety and depression scale.

\begin{tabular}{|c|c|c|c|}
\hline HAD anxiety & WITH ULCER & WITHOUT ULCER & CONTROLS \\
\hline I feel tensed or wound up & $16 \%$ & $0 \%$ & $4 \%$ \\
\hline $\begin{array}{l}\text { I get sort of frightened feeling as if something awful is about } \\
\text { to happen }\end{array}$ & $52 \%$ & $36 \%$ & $20 \%$ \\
\hline Worrying thought go through my mind & $76 \%$ & $32 \%$ & $32 \%$ \\
\hline I can sit as ease and feel relaxed & $4 \%$ & $12 \%$ & $8 \%$ \\
\hline I get a sort of frightened feeling like butterflies in the stomach & $4 \%$ & $8 \%$ & $12 \%$ \\
\hline I feel restless as I have to be on the move & $12 \%$ & $8 \%$ & $8 \%$ \\
\hline I get sudden feeling of panic & $28 \%$ & $8 \%$ & $24 \%$ \\
\hline \multicolumn{4}{|l|}{ HAD depression } \\
\hline I still enjoy the things I used to enjoy & $12 \%$ & $12 \%$ & $4 \%$ \\
\hline I can laugh and see the funny side of things & $16 \%$ & $4 \%$ & $8 \%$ \\
\hline I feel cheerful & $4 \%$ & $8 \%$ & $0 \%$ \\
\hline I feel as if $i$ am slowed down & $8 \%$ & $16 \%$ & $8 \%$ \\
\hline I have lost interest in my appearance & $28 \%$ & $12 \%$ & $24 \%$ \\
\hline I look forward with enjoyment to things & $8 \%$ & $16 \%$ & $8 \%$ \\
\hline I can enjoy a good book or radio or tv program & $4 \%$ & $8 \%$ & $8 \%$ \\
\hline
\end{tabular}

*HAD $=$ Hospital Anxiety and Depression

Patients with previous history of ulcer had more stress and depression levels in comparison to controls. GHQ questionnaire responses demonstrated twice increase in stress levels for test groups than controls as most of them were not able to concentrate, we're not able to take their own decisions, overcome difficulties, faced problems, lacked confidence and were unhappy. The psychological impact was also more in test group patients as they were tensed, worried and had a feeling of panic.

\section{Discussion}

RAS are single or multiple painful ulcerations that usually occur on non-keratinized mucosa of the oral cavity and appear as yellowish white ulcerations, surrounded by an erythematous halo. It affects $20 \%$ of the general population with a predilection for females, commonly seen in children and young adults, and after a time tends to decrease both in severity and frequency. The exact etiology of RAS still remains unclear, and multiple factors have been considered in the exacerbation of RAS such as genetic predisposition, local trauma, allergy to certain food materials, vitamin deficiency, immunosuppression, smoking and psychiatric factors (stress and anxiety) (6). Psychological stress is considered as a common provoking or trigger factor in the occurrence and progression of RAS, but little documentation has been presented to substantiate this widely held assumption (7-9). This particular study was carried out to establish an association between RAS, stress, anxiety and depression by use of General Health Questionnaire, and Hospital anxiety and Depression scale. 25 cases of RAS patients were included in the present study with age range 16-55 years, the demographic data was similar to the study by Gallo et al. (10) in which the mean age of the RAS patients in test group was 23.5 years and control group 24.4 years. Out of 75 subjects, male patients accounted for $33.3 \%$, and female patients accounted for $66.7 \%$, with a male to female ratio of $1: 2$ in accordance with studies by Ship (11) Gallo et al. (10) that reported female predilection for RAS.

Life's stress is a product of the changes that occur in one's life that require adaptation, coping and social readjustment (12), and often it may disturb the psychic equilibrium, producing maladaptive patterns and possibly physical and mental disorders (13-15). Higher levels of anxiety were associated with recurrent ulcers which may be because of transient and episodic stressful situations that trigger certain mechanisms (such as transitory increase of salivary cortisol and stimulation of immune-regulatory activity by increasing the number of leukocytes at sites of inflammation) $(7,14)$. In the present study, patients with RAS reported slightly higher levels of anxiety (8.04 \pm 3.49$)$ than controls (7.04 \pm 5.10$)$, and this association was in agreement with the studies by Buajeeb et al. (13) Gallo et al. (10) and Soto-Araya et

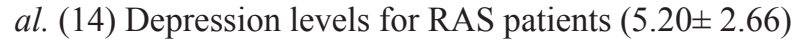
were also higher when compared to control group (3.96 \pm 2.93 ), but the difference was statistically not significant (0.711), this finding was similar to the results obtained by Mc Cartan et al. (7) and Soto -Araya et al. (14) in which no statistically significant relationship was demonstrated between depression and RAS. 
When patients with RAS were evaluated by the psychometric test using GHQ score, it was observed that the mean GHQ score for test group 1 was $9.76 \pm 4.52$ which was comparable to control group $9.72 \pm 5.01(\mathrm{p}=0.526)$ but higher levels were observed for test group 2 (11.48 \pm $5.66, \mathrm{p}=0.397)$, and the difference was not statistically significant, this shows that patients with ulcer history were having slightly more stress and those with RAS at present had similar stress levels as normal individuals. Contrary to above observation, Pedersen A (9), Andrews and Hall (16), Zwiri et al. (17) Sherman et al. (18) reported no association between RAS and stressful events or symptoms of anxiety, hence the authors concluded that the psychological factors were neither important, in the etiopathogenesis nor in the severity of the RAS.

\section{Conclusions}

This study suggested impact of psychological factors such as anxiety, stress and depression on the quality of life of RAS patients. Although depression and anxiety levels were comparable to normal individuals, but psychological stress was found to be an important trigger factor for the initiation of recurrent ulcers. More survey based questionnaire studies or clinical trials should be encouraged for establishment of a significant relationship between psychological status and RAS.

\section{References}

1. Preeti L, Magesh K, Rajkumar K, Karthik R. Recurrent aphthous stomatitis. J Oral Maxillofac Pathol. 2011;15:252-6.

2. Nadendla LK, Meduri V, Paramkusam G, Pachava KR. Relationship of salivary cortisol and anxiety in recurrent aphthous stomatitis. Indian Journal of Endocrinology and Metabolism. 2015;19:56-9.

3. Gurleyen EK, Ogut-Erisen M, Onur Cakır, Omer Uysal, Gulsum Ak. Quality of life in patients with recurrent aphtous stomatitis treated with a mucoadhesive patch containing citrus essential oil. Patient prefer adherence. 2016;27:967-73.

4. Ajmal M, Ibrahim I, Mohammed N, Al-qarni H. Prevalence and psychological stress in recurrent aphthous stomatitis among female dental students in Saudi Arabia. Clujul Med. 2018;91:216-21.

5. Tabolli S, Bergamo F, Alessandroni L, Di Pietro C, Sampogna F, Abeni D, Quality of Life and Psychological Problems of Patients with Oral Mucosal Disease in Dermatological Practice. Dermatology. 2009;218:314-20.

6. Casiglia JM. Recurrent aphthous stomatitis: Etiology, diagnosis and treatment. Gen Dent. 2002;50:157-66.

7. Mc Cartan BE, Lamey PJ, Wallace AM. Salivary cortisol and anxiety in recurrent aphthous stomatitis. J Oral Pathol Med. 1996;25:357-9.

8. Albanidou-Farmaki E, Poulopoulos AK, Epivatianos A, Farmakis $\mathrm{K}$, Karamouzis M, Antoniades D. Increased anxiety level and high salivary and serum cortisol concentrations in patients with recurrent aphthous stomatitis. Tohoku J Exp Med. 2008;214:291-6.

9. Pederson A. Psychologic stress and recurrent Aphthous ulceration. J Oral Pathol Med. 1989;18:119-22.

10. Gallo CB, Mimura MAM, Sugaya NN. Psychological stress and recurrent aphthous stomatitis. Clinics. 2009;64:645-8.

11. Ship II. Epidemiologic aspects of recurrent aphthous ulcerations. Oral Surg Oral Med Oral Pathol. 1972;33:400-6.

12. Ng V, Koh D, Chia SE. Examination stress, salivary cortisol, and academic performance. Psychol Rep. 2003;93:1133-4.

13. Buajeeb W, Laohapand P, Vongsavan N, Kraivaphan P. Anxie- ty in recurrent aphthous stomatitis patients. J Dent Assoc Thai. 1990;40:253-8.

14. Soto-Araya M, Rojas-Alcayaga G, Esguep A. Association between psychological disorders and the presence of oral lichen planus, burning mouth syndrome and recurrent aphthous stomatitis. Med Oral. 2004;9:1-7.

15. Redwine L, Snow S, Mills P, Irwin M. Acute psychological stress: effects on chemotaxis and cellular adhesion molecule expression. Psychosom Med. 2003;65:598-603.

16. Andrews VH, Hall HR. The effects of relaxation/imagery training on recurrent aphthous stomatitis: a preliminary study. Psychosom Med. 1990;52:526-35.

17. Zwiri AM. Anxiety, Depression and Quality of Life among Patients with Recurrent Aphthous Ulcers. J Contemp Dent Pract. 2015;16:1127.

18. Sherman JJ, Barach R, Whitcomb KK, Haley J, Martin MD. Pain and pain-related interference associated with recurrent aphthous ulcers. J Orofac Pain. 2007;21:99-106.

\section{Conflict of Interest}

The authors have declared that no conflict of interest exist. 